\title{
Comparative Study of Polypropylene Non-Woven Surgical Mask and Locally Manufactured Woven and Knitted Fabrics Facial Masks
}

\author{
Edem Kwami Buami' ${ }^{1}$ Charles Kumah ${ }^{1 *}{ }^{\circledR}$, Divine Vigbedor', Rejoice Makafui Tsotorvor2, \\ Ruru Pan ${ }^{3}$ \\ ${ }^{1}$ Department of Industrial Art, Ho Technical University, Ho Volta Region, Ghana \\ ${ }^{2}$ Visual Art Department, Akatsi College of Education, Akatsi, Volta Region, Ghana \\ ${ }^{3}$ Key Laboratory of Eco-textiles, Ministry of Education, School of Textile \& Clothing, Jiangnan University, Wuxi, China

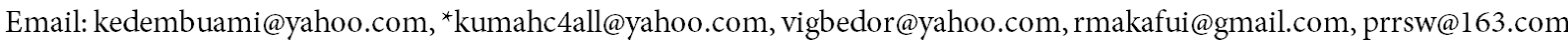

How to cite this paper: Buami, E.K., Kumah, C., Vigbedor, D., Tsotorvor, R.M. and Pan, R. (2021) Comparative Study of Polypropylene Non-Woven Surgical Mask and Locally Manufactured Woven and Knitted Fabrics Facial Masks. Journal of Textile Science and Technology, 7, 131-141.

https://doi.org/10.4236/jtst.2021.73011

Received: June 29, 2021

Accepted: August 3, 2021

Published: August 6, 2021

Copyright $\odot 2021$ by author(s) and Scientific Research Publishing Inc. This work is licensed under the Creative Commons Attribution International License (CC BY 4.0).

http://creativecommons.org/licenses/by/4.0/

\begin{abstract}
The outbreak of coronavirus has led to an increase in the demand for facemasks globally. Unavailability of appropriate polypropylene non-woven fabrics face masks as a result of inadequate supply to satisfy the growing population has brought about the manufacturing of locally fabrics masks to augment or substitute standard medical class facemasks. The study aims at analyzing airflow of these locally manufactured fabrics to determine possible means of transmitting the virus as well as establish comfort of the user of these masks. Standard polypropylene non-woven, woven and knitted fabrics were considered for the study. Air permeability test was conducted on these fabrics using Frazier Air permeability tester. Depending on the property significant variation in the textile fabrics, polypropylene non-woven is widely accepted for facial masks. Nevertheless, this study illustrates that woven and knitted fabrics have more open structures, which allow a high rate of air penetration and so may require two or three layers to prevent antimicrobial or antiviral potential.
\end{abstract}

\section{Keywords}

Polypropylene Non-Woven Fabric, Woven Fabric, Knitted Fabric, Facial Mask, Air Permeability

\section{Introduction}

Masks have been used since ancient times for ceremonial, protective and prac- 
tical purposes, as well as in recreational activities. Masks are categorized into Surgical cover; originally developed to contain and filter droplets of microorganisms expelled from the mouth and nasopharynx of healthcare workers and patients during surgery and general medical practices in and around hospital environment. Desai noted that a mask is a covering made up of fibre or gauze and fitting over the nose and mouth to protect against air pollutants, or made of sterile gauze and worn to protect infection of the wearer [1]. The primary purpose of a surgical mask is to provide protection for the vulnerable from the surgical/medical team [2]. Also, ceremonial masks are developed mainly for recreations and for certain religious practices [3].

Recently, wearing personal protective facemasks have been thought to provide an immediate and short-term practical solution to individuals globally, who seek to reduce their exposure to high levels of pandemic and air pollution without having to avoid highly polluted environments [4]. Locally manufactured textiles or Cloth masks lately have become popular choices, particularly in the developing world due to easy accessibility and affordability. The covid-19 pandemic has taught citizens from developing countries the necessity to mask up which has adopted the sense of creativity among the youth by manufacturing various brands of cloth masks. Dan Wang et' al stated that If it is safe to do so, the use of both surgical and local cloth masks during the COVID-19 pandemic may be suitably prolonged following technical recommendations possibly from World Health Organization (WHO) [5]. People in low-risk areas on the other hand, particularly are advised to reuse masks [5]. Nevertheless, all local masks must attain standards primarily to address the function of disposable masks, with no explicit directions for mask performance for alternative functions, such as single-use period, cleaning techniques, or the number of times a mask can be properly reused [6]. Disposable medical masks, surgical masks, medical protective masks, and dust masks often comprised of nonwoven polypropylene textile with electrostatic characteristics that improve particle collection as required by facial masks.

Since the affirmation of COVID-19 as a pandemic by the World Health Organization, there have been a number of preventive measures outlined by some organization to minimize the risk of being infected with the virus. Examples of these preventive measures includes but not limited to; regular washing of hands with soap under running water, the use of alcohol based hand sanitizers of alcohol concentration $70 \%$ to $80 \%$, social distancing of at least about one metre, avoiding overcrowding and ensuring good ventilation, as well as wearing of face mask [7]. Even though cloth mask agreeably may not be effective during the pandemic [8], its assessment of controlling the spread of the covid-19 pandemic and other air borne diseases cannot be under estimated [9]. It is now known that, COVID-19 is transmitted predominantly by inhalation of respiratory droplets generated when people cough, sneeze, sing, talk or breathe [10]. Hence the use of the mask is intended not only to reduce the risk of infection by inhala- 
tion but also to reduce the emission of the virus. According to Ghana Health Service, a report from the daily graphic dated March $16^{\text {th }}, 2020$, there has been an increased demand of face mask in developing countries especially in Ghana since the first case of COVID-19 was reported in Ghana, March $12^{\text {th }}, 2020$. As a result, there is hike in the price of surgical masks. This has led to a lot of people resorting to the use of face masks made from cloth.

Although both surgical mask and locally cloth face mask offer some protection from droplet of infection, the former according to a research offers better protection than the latter [4]. Polypropylene non-woven surgical face masks come in various thicknesses. Some are three-ply while others are four-ply of non-woven materials. This impacts their ability to protect one from splashes, sprays, large particle droplets or splatters that may contain viruses or bacteria [4] [11]. In an extensive review of various face masks published in September 2020 in the Journal of Science Advance, researchers from Duke University, found surgical masks to be the second best option to protect one from COVID-19 infection. Alternative benefit of the use of the surgical mask is that they are single-used and are disposable.

On the other hand, locally woven cloth face mask became an alternative for many who could not acquire the surgical face mask due to the scarcity and hiked price [9]. Strategically, it is less expensive and reusable. It is however worth noting that, its reusability can become detrimental when it is not well disinfected before reuse. Also, locally woven cloth face mask can be in layers of at most three materials. A research shows that the locally woven face mask can offer about $50 \%$ or even more protection when it is made up of three layers [7] [12]. Nonetheless, it is relevant to know that cloth mask doesn't provide the same level of protection as surgical face masks. According to C Raina et al., moisture retention, reuse of woven cloth face mask and poor filtration may result in increased risk of infection [13]. Woven cloth face mask is reusable and must be disinfected for reuse [10] [14]. One challenge is that most people don't have the requisite knowledge to properly disinfect the woven cloth face mask before reuse and also, most of these face mask are made from a very thick fabrics and as such has a very little air penetration even if it is able to trap particles of viruses and other germs.

Surgical masks conspicuously, are loose-fitting masks that have been approved by the food and drug authority (FDA). In comparison to fabric masks, surgical face masks are manufactured under extremely hygienic conditions. This mask prevents big droplets of bodily fluids containing the virus or other germs from escaping through an infected person [15]. They also shield you from other people's splashes and sprays, such as sneezes and coughs. Surgical face masks are also disposable, which means they're only used once. Disposing them after usage minimizes the chance of infection from the virus and other germs that may have lodged in it during the initial use. Additionally, surgical masks are rather loose, resulting in a high risk of infection and have air filtration [16]. It should be 
noted also that locally woven cloth facial masks can be made under good hygienic conditions meeting all expected requirement of surgical face masks.

This study however, analyses the effectiveness of both polypropylene nonwoven surgical and locally manufactured woven and knitted cloth masks and presents some recommendations to enhance the effectiveness of the locally manufactured woven cloth masks.

\section{Materials and Methods}

According to research [17] [18], The purpose of a woven and knitted cloth face mask is to function as a protective border to incredibly tiny droplets produced during talking, sneezing, or coughing, which can be up to 5 microns in size (WHO 29/4/2020). When one is exposed to coughing and sneezing, every facial masks, including N95 or locally manufactured fabric, filter less tiny particles than when exposed to regular breathing rate of human. This study was conducted using the following textile fabrics: polypropylene non-woven, woven, and knitted fabrics. Frazier air permeability tester was used to determine the flow and speed of passage of air through the above-mentioned fabrics.

Figure 1 is the sample textile fabrics that were tested with the air permeability tester.

The estimated airflow over an area of the fabric at a specific magnitude is known to be the air permeability of a fabric filter medium [19]. This approach was used to determine the reasonable of air resistance by measuring the time it took to flow to a certain volume of air through it at a given pressure. The conventional method for determining the air permeability of a fabric is to set the device flow rate after calibration and analyse the airflow. The air is sucked through the clamped medium specimen into an enclosed chamber and out through an outlet that measures the flow.

The rate of air per unit area is given as a differential pressure which is expressed as $\mathrm{cfm} / \mathrm{ft}$ at 0.5 inches, (cubic feet per square feet of sample per minute)/(feet per minute). Regular rating for the experiment is estimated from 2 to $2000 \mathrm{~Pa}$, at a permeability range of $0.1-12,000 \mathrm{~mm} / \mathrm{s}$. The testing area covers 20 $\mathrm{cm}^{2}$. The result will be the relative per size, so a small number would provide finer removal efficiency. ASTM D737-04 is the standard test method of air permeability of textile fabrics [20].

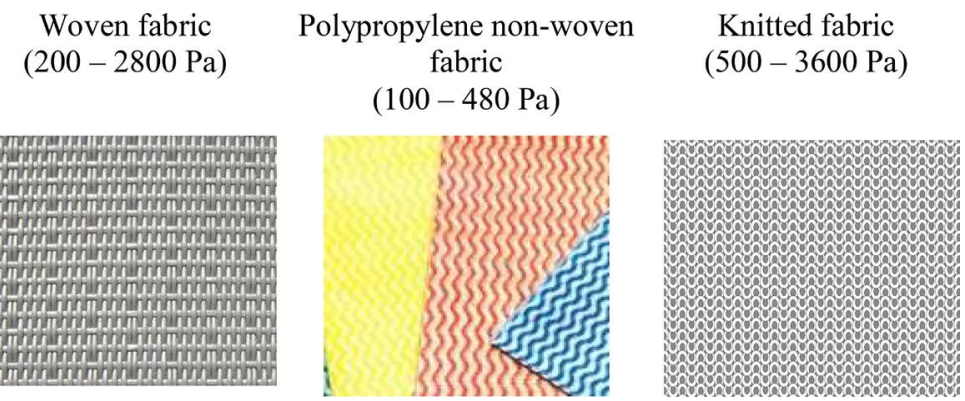

Figure 1. Textile fabrics (woven, non-woven, and knitted fabrics). 
The Frazier Air Permeability tester, manufactured by the Frazier Precision Instrument Company, Inc., Hagarstown, Maryland USA, is illustrated in Figure 2.

Figure 2, is an outline representation of Frazier air permeability tester (The Frazier Air Permeability tester, manufactured by the Frazier Precision Instrument Company, Inc., Hagarstown, Maryland USA), sucked the air into an enclosed chamber through the clamped medium fabric and out through an aperture that measures the flow. For airflow calculation, a manometer across the medium delivers the pressure globule, whereas a manometer across the nozzle gives the pressure globule across the nozzle for evaluation of airflow.

\section{Results and Discussion}

Air permeability is one of the most important characteristics in the functioning of fabrics for facial mask in the prevention of air borne diseases as they aid as

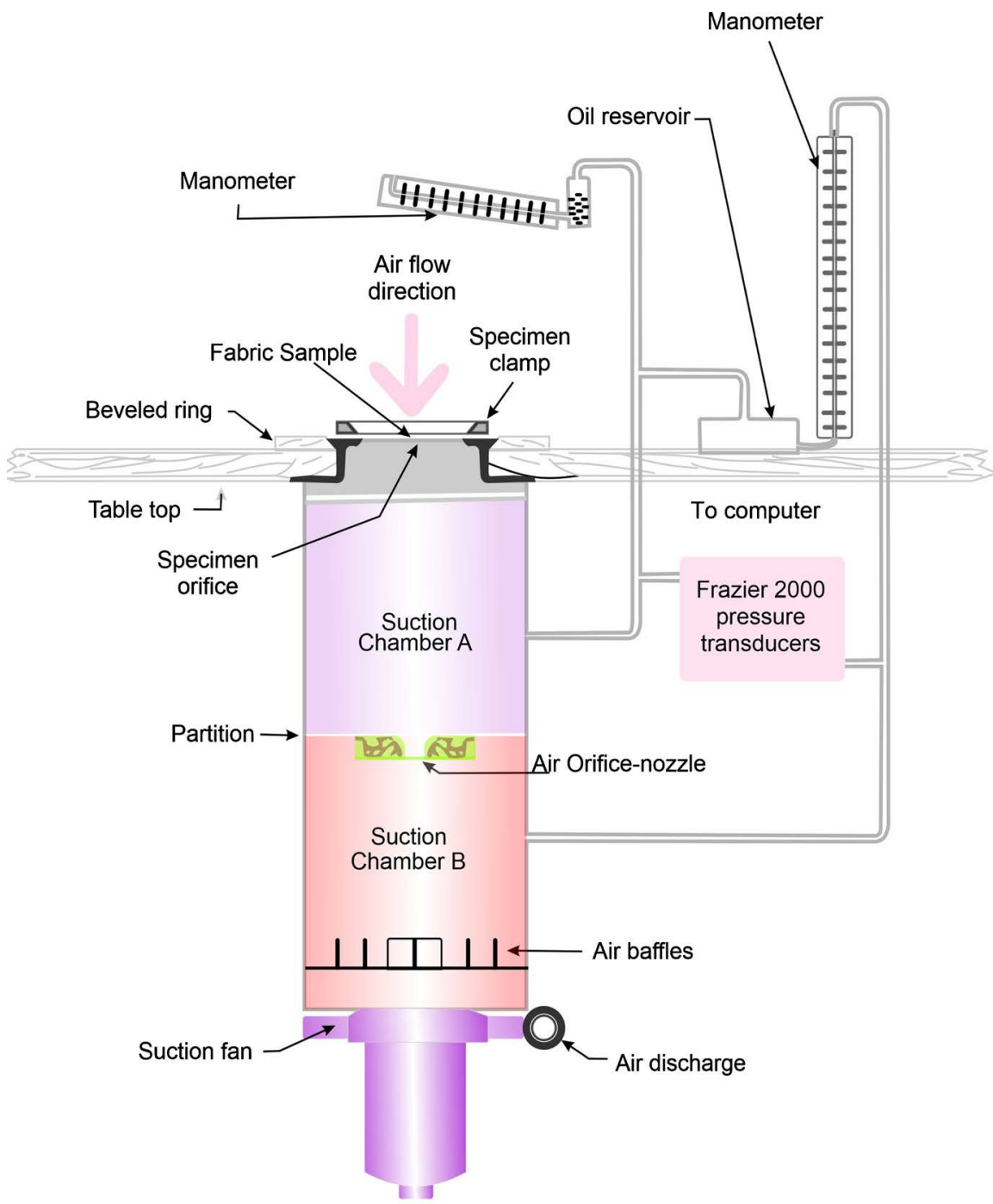

(Source: Adapted from ScienceDirect, 2021).

Figure 2. Frazier air permeability tester (The Frazier Air Permeability tester, manufactured by the Frazier Precision Instrument Company, Inc., Hagarstown, Maryland USA). 
filter, breathable liners, protective clothing and other applications in medical, industrial and home clothing [21] [22]. Relatively, it delivers assessment of fabric permeability to thickness and density. Fabric Thickness is a parameter which controls handle, creasing, thermal resistance, heaviness or stiffness.

This study shows that yarn twist of the woven fabrics contribute significantly to increase in circular and density of the fabric simultaneously decreasing the diameter and further increasing the high rate of air passage [23], it records about $2800 \mathrm{~Pa}$. Also, yarn crimp demonstrate high rate of fabric opening causing extension, increase in free space which permit high air permeability. In yarn construction, yarns are modified by increasing the twist for special effect, this correspondingly permit spherical, and high-density yarns to be crammed tightly together in complex woven structure with much lower air permeability.

The airflow per unit area through the polypropylene non-woven was evaluated at a specified variance pressure, usually about $480 \mathrm{~Pa}$. As per the accuracy of measurement, the technique seems rather very useful for prompt determination of quality and uniformity of polypropylene non-woven material. The most important element such as base weight, fabric thickness, and ostensible density define airflow as well the speed. There are also major determining factors such as size of fibres, and method of construction. However, airflow reduces drastically on the bases of base thickness, and probably conspicuous density increase in space and decrease in fibre size [24] [25].

On the other hand, knitted fabric proves to permit high rate of air permeability based on the study we conducted. Knitted fabric is a textile material made by inter-looping yarns or inter-meshing loops, a process known as knitting. It differs from woven and non-woven cloths in that it is more flexible and can be formed into smaller pieces more easily. Due to its flexibility, it is more susceptible to airflow even though it is more bulky compare to woven and non-woven fabrics. It measures about $3600 \mathrm{~Pa}$. Figure 3 below shows the graphical representation of air permeability between the three types of textile fabrics used for the study.

It is widely thought that air permeability of fabric is determined by its air porosity which defines its openness. More fabric porosity results in a more permeable fabric. As a result, air permeability is directly relative to the pressure. When comparing the air permeability of the three fabrics, knitted fabric had the highest air permeability. Nonetheless, this airflow is associated with the fabric's porous structure that is equivalent to the rate of fabric porosity [26]. Also, when the pressure level sprouts, the flow rate rises.

The study reveals that the porous nature of woven and knitted fabrics permit high rate of airflow compared to non-woven and could not be substituted for polypropylene non-woven surgical masks as best for prevention of air borne diseases as seen in Figure 3. Due to the circumstances, WHO has approved production of disposal surgical masks and all protective masks made of non-woven polypropylene fabric having electrostatic properties which will capture tiny particles and micro-organisms [5]. 


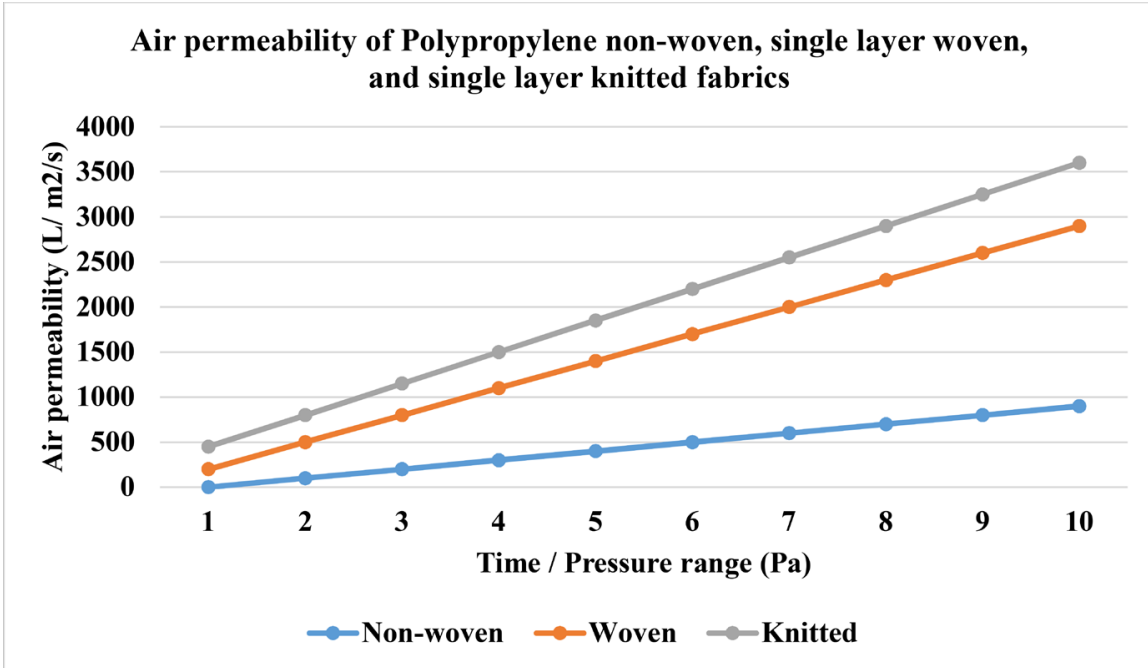

Figure 3. Air permeability of non-woven, woven, and knitted fabrics.

Nevertheless, the appearance of the locally manufactured fabric masks made up of woven and knitted create high awareness of the pandemic and perhaps other related air borne diseases. Individuals however, who pushed out of inevitability to reuse facial masks thereby considering locally manufactured fabric masks should consider extending the use of masks that were originally designed as disposable masks making it user-friendly by sanitization to kill any COVID-19 viruses on the used masks; and also, efficiently controlled charge regeneration of masks to maintain mask performance for reuse [5] [8].

The study was also conducted on two and three layers of woven and knitted fabrics respectively and compared with polypropylene non-woven fabric. Results indicate that an increase in the number of fabric layers will improve efficiency and additional protection for the user, nonetheless, they have reverse effect on breathability of the user. Figure 4 and Figure 5 show graphical representation of two and three layers respectively.

Air permeability test for the three types of fabric was conducted within a time frame of $10-15 \mathrm{~s}$. Figure 4 illustrate a reduction in airflow and Figure 5 further reduction thereby increasing additional protection but high breathability consequence by the user. Air permeability on the y-axis illustrates the flow of air with its corresponding to time/pressure range $(\mathrm{Pa})$ on the $\mathrm{x}$-axis. The axes show the time correlation between the rate of air movement of each fabric.

From Table 1, after the enormous reduction from a single layer woven fabric, there is little or no reduction between two and three layers woven fabrics. In order not to have further breathability effect, two or three layers woven fabric is recommended for facial mask. In the case of knitted fabric layers, substantial reduction is observed between two and three layers signifying how porous knitted fabrics could be hence high rate of air permeability. The greater the air permeability is, it improved breathability and comfort but with higher risk of contamination and transmission. 


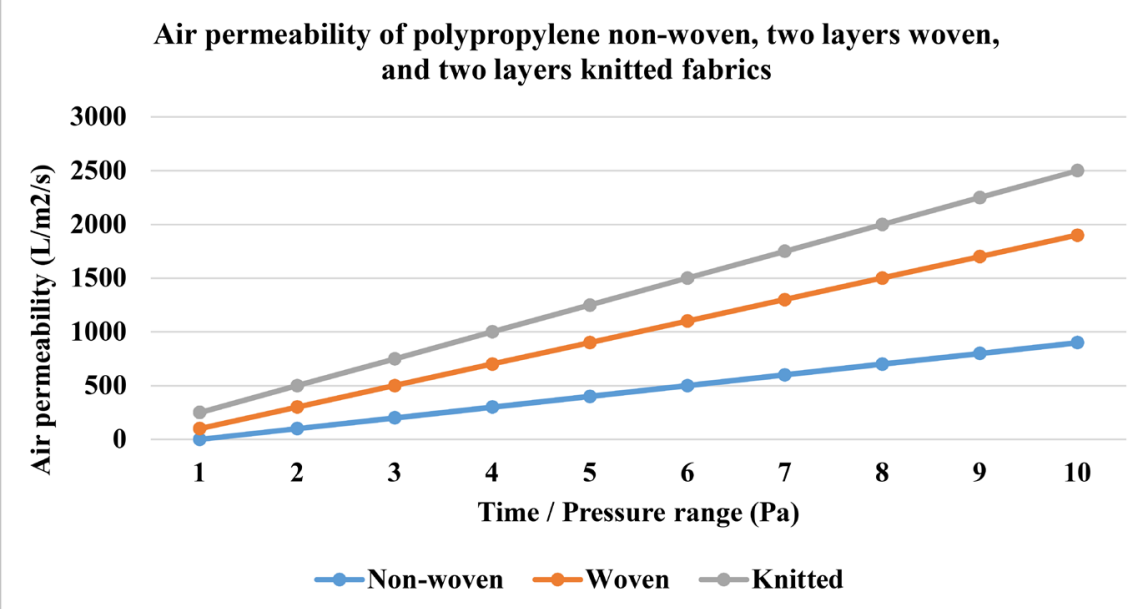

Figure 4. Air permeability of polypropylene non-woven, two layers woven, three layers knitted fabrics.

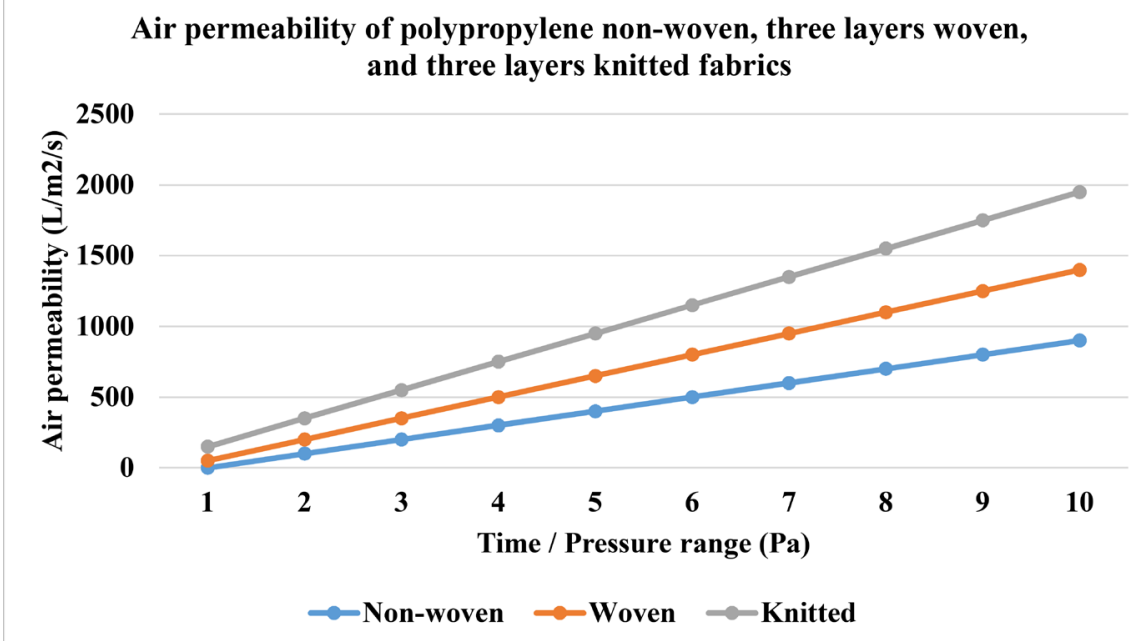

Figure 5. Air permeability of polypropylene non-woven, three layers woven, three layers knitted fabrics.

Table 1. Below illustrate the relationship between the differential values of the three types of fabrics shown in the graphs.

\begin{tabular}{ccc}
\hline Fabric type & Air permeability flow $(\mathrm{Pa})\left(\mathrm{L} / \mathrm{m}^{2} / \mathrm{s}\right)$ & Time $(\mathrm{s})$ \\
\hline Polypropylene non-woven & $100-480$ & $10-15 \mathrm{~s}$ \\
Woven-single layer & $200-2800$ & $10-15 \mathrm{~s}$ \\
Woven-two layers & $200-1800$ & $10-15 \mathrm{~s}$ \\
Woven-three layers & $100-1800$ & $10-15 \mathrm{~s}$ \\
Knitted-single layer & $500-3600$ & $10-15 \mathrm{~s}$ \\
Knitted-two layers & $300-2500$ & $10-15 \mathrm{~s}$ \\
Knitted-three layers & $200-1900$ & $10-15 \mathrm{~s}$ \\
\hline
\end{tabular}

Shortages of standard polypropylene non-woven masks globally and in Ghana from research show that individuals should not depend on scarce resources at 
the expense of the most vulnerable health workers in line of duty [6], rather focus on locally manufactured woven as well knitted face masks taking into consideration lay down requirement or guidelines by WHO. Precisely, consider the fact that the virus seems to predominantly come out during talking or sneezing of an infected person [27]. Fabrics and probable liners or filters if selected carefully under good hygienic conditions for users can offer significant role in reducing the spread of the virus and other air borne diseases in the community [27] [28].

Accordingly, all masks must be well design to allow breathing and comfort. If the mask averts individuals from breathing easily, it will cost a serious danger to the health, not only from becoming oxygen deprived but also risking individuals to touch the face and remove or adjust the mask during wear which may increase excessive risk of transmission.

\section{Conclusions}

The study considerably employed three different fabrics under discussion namely, polypropylene non-woven, woven, and knitted fabrics based on their air permeability using Frazier Air permeability tester.

Polypropylene non-woven fabrics mostly are held together with a bonding agent which largely determine the wear properties of the fabric and also the breathability nature of the fabric structure. Even though the air penetration rate is low as compared to woven and knitted fabrics from this study, it does prevent the transmission of the virus and other related air borne infections. We observed that knitted fabric having the highest amount of air penetration due to its open structures, which allows a high level of stretch. Also, woven fabrics are higher than of non-woven due to the interlacing of the warp and weft yarns, which are enhanced by beat-ups with the reed. The increasing rate of manufacturing facemasks locally using woven and knitted fabrics have brought to the fore light the need to consider the variable that directly and simultaneously influences mask breathability and effectiveness providing comfort and some additional protection. Accordingly, woven fabric masks can replace non-woven masks to reduce pressure on scarcity of economy of the developing countries especially Ghana. We also recommend that it should be produced considering full requirements of World Health Organization.

Additionally, locally woven and knitted fabrics masks should be made with layers of two or three in order to lower the risk in acquiring the virus or any infectious diseases. Also, all masks should be accompanied by directives elucidating how it should be worn and cared for and what the limitations of a mask are and when the mask or its components must be replaced.

\section{Conflicts of Interest}

The authors declare no conflicts of interest regarding the publication of this paper. 


\section{References}

[1] Desai, A.N. and Mehrotra, P. (2020) Medical Masks. JAMA, 323, 1517-1518. https://doi.org/10.1001/jama.2020.2331

[2] Desai, A.N. and Aronoff, D.M. (2020) Masks and Coronavirus Disease 2019 (COVID-19). JAMA, 323, 2103-2103. https://doi.org/10.1001/jama.2020.6437

[3] Hawker, R.W. (2018) Chapter Three. Masks and Ceremonial Objects. In: Yakuglas Legacy, University of Toronto Press, Toronto, 73-116.

[4] Teesing, G., et al. (2020) Is There an Adequate Alternative to Commercially Manufactured Face Masks? A Comparison of Various Materials and Forms. Journal of Hospital Infection, 106, 246-253. https://doi.org/10.1016/j.jhin.2020.07.024

[5] Wang, D., et al. (2020) Can Masks Be Reused after Hot Water Decontamination during the COVID-19 Pandemic? Engineering, 6, 1115-1121. https://doi.org/10.1016/j.eng.2020.05.016

[6] Oppong, J.R., Dadson, Y.A. and Ansah, H. (2021) Africa's Innovation and Creative Response to COVID-19. African Geographical Review, 1-18. https://doi.org/10.1080/19376812.2021.1897635

[7] Wang, D., et al. (2020) Selection of Homemade Mask Materials for Preventing Transmission of COVID-19: A Laboratory Study. PLoS ONE, 15, e0240285. https://doi.org/10.1371/journal.pone.0240285

[8] Mueller, A.V., et al. (2020) Quantitative Method for Comparative Assessment of Particle Removal Efficiency of Fabric Masks as Alternatives to Standard Surgical Masks for PPE. Matter, 3, 950-962. https://doi.org/10.1016/j.matt.2020.07.006

[9] Mueller, A.V. and Fernandez, L.A. (2020) Assessment of Fabric Masks as Alternatives to Standard Surgical Masks in Terms of Particle Filtration Efficiency.

[10] Organization, W.H. (2020) Advice on the Use of Masks in the Context of COVID-19: Interim Guidance, 6 April 2020. World Health Organization, Geneva.

[11] Grigg, S.E., et al. (2020) Are Surgical Masks Manufactured from Sterilisation Wrap Safe? Infection, Disease \& Health, 26, 104-109.

[12] van Straten, B., et al. (2021) A Life Cycle Assessment of Reprocessing Face Masks during the Covid-19 Pandemic. https://doi.org/10.21203/rs.3.rs-148523/v1

[13] MacIntyre, C.R., et al. (2015) A Cluster Randomised Trial of Cloth Masks Compared with Medical Masks in Healthcare Workers. BMJ Open, 5, e006577. https://doi.org/10.1136/bmjopen-2014-006577

[14] Organization, W.H. (2020) Rational Use of Personal Protective Equipment (PPE) for Coronavirus Disease (COVID-19): Interim Guidance, 19 March 2020. World Health Organization, Geneva.

[15] Wamungu, Q.G., et al. (2020) The Effectiveness of Different Types of Face Masks. Archives of Pulmonology and Respiratory Care, 6, 68-71. https://doi.org/10.17352/aprc.000059

[16] Akduman, C. and Kumbasar, E.A. (2018) Nanofibers in Face Masks and Respirators to Provide Better Protection. IOP Conference Series. Materials Science and Engineering, 460, Article ID: 012013. https://doi.org/10.1088/1757-899X/460/1/012013

[17] van Rensburg, D., et al. (2020) Year of the Face Mask: Do's and Don'ts during Exercise. South African Journal of Sports Medicine, 32, 1-2. https://doi.org/10.17159/2078-516X/2020/v32i1a8615

[18] Liao, M., et al. (2021) A Technical Review of Face Mask Wearing in Preventing Respiratory COVID-19 Transmission. Current Opinion in Colloid \& Interface Science, 
2021, Article ID: 101417. https://doi.org/10.1016/j.cocis.2021.101417

[19] Abuzade, R.A., Zadhoush, A. and Gharehaghaji, A.A. (2012) Air Permeability of Electrospun Polyacrylonitrile Nanoweb. Journal of Applied Polymer Science, 126, 232-243. https://doi.org/10.1002/app.36774

[20] Razzaque, A., et al. (2017) Investigation on Hydrostatic Resistance and Thermal Performance of Layered Waterproof Breathable Fabrics. Fibers and Polymers, 18, 1924-1930. https://doi.org/10.1007/s12221-017-1154-1

[21] Lee, K.-P., et al. (2020) Reusable Face Masks as Alternative for Disposable Medical Masks: Factors That Affect Their Wear-Comfort. International Journal of Environmental Research and Public Health, 17, 6623.

https://doi.org/10.3390/ijerph17186623

[22] Li, Y., et al. (2006) Antimicrobial Effect of Surgical Masks Coated with Nanoparticles. Journal of Hospital Infection, 62, 58-63.

https://doi.org/10.1016/j.jhin.2005.04.015

[23] Atalie, D., Tesema, A.F. and Rotich, G.K. (2018) Effect of Weft Yarn Twist Level on Thermal Comfort of 100 Percent Cotton Woven Fabrics. Research Journal of Textile and Apparel, 22, 180-194. https://doi.org/10.1186/s40691-018-0169-6

[24] Paxton, N.C., et al. (2020) N95 Respiratory Masks for COVID-19: A Review of the Literature to Inform Local Responses to Global Shortages.

[25] Bayona, H.H.G. and Infantado, M.A.J. (2020) Are Cloth Masks Effective in Preventing COVID-19 Infections?

[26] Kanakaraj, P., Ramachandran, R. and Dasaradan, B. (2011) Air Permeability Behavior in Multi Layer Weft Knit Fabrics. Rising India, 90, 90.

[27] Mwema, F. and Nyika, J. (2020) Challenges in Facemake Use and Potential Solutions: The Case Study of Kenya. Scientific African, 10, e00563.

https://doi.org/10.1016/j.sciaf.2020.e00563

[28] Organization, W.H. (2020) Advice on the Use of Masks in the Context of COVID-19: Interim Guidance, 5 June 2020. World Health Organization, Geneva. 